1. Hershko, A. \& Ciechanover, A. Annu. Rev. Biochem. 67, 425-479 (1998).

2. Thrower, J.S., Hoffman, L., Rechsteiner, M. \& Pickart, C.E. EMBO J. 19, 94-102 (2000).

3. Voges, D., Zwickl, P. \& Baumeister, W. Annu. Rev. Biochem. 68, 1015-1068 (1999).

4. Braun, B.C. et al. Nat. Cell Biol. 1, 221-226 (1999).

5. Bercovich, Z., Rosenberg-Hasson, Y., Ciechanover, A. \& Kahana, C. J. Biol. Chem. 264, 15949-15952 (1989).

6. Zhang, M., Pickart, C.M. \& Coffino, P. EMBO J. 22, 1488-1496 (2003).

7. Prakash, S., Tian, L., Ratliff, K.S., Lehotzky, R.E. \&

\section{Reading ratios} that specify distinct cell fates at different concentrations. The second part has to do with the cell's ability to 'read' gradients via cell surface receptors that bind these morphogens and convert that signal into transcriptional outputs.

For most morphogens, it is unclear how the signal and its receptor cooperate to provide cells with positional information. Casali and Struhl (Nature
Matouschek, A. Nat. Struct. Mol. Biol. 11, 830-837 (2004).

8. Dougan, D.A., Mogk, A., Zeth, K., Turgay, K. \& Bukau, B. FEBS Lett. 529, 6-10 (2002).

9. Neher, S.B., Sauer, R.T. \& Baker, T.A. Proc. Natl Acad. Sci. USA 100, 13219-13224 (2003).

10. Keiler, K.C., Waller, P.R.H. \& Sauer, R.T. Science 271, 990-993 (1996).

11. Levchenko, I., Seidel, M., Sauer, R.T. \& Baker, T.A. Science 289, 2354-2356 (2000).

12. Wah, D.A. et al. Mol. Cell 12, 355-363 (2003).

13. Siddiqui, S.M., Sauer, R.T. \& Baker, T.A. Genes Dev. 18, 369-374 (2004)

14. Glickman, M.H. et al. Cell 94, 615-623 (1998).
15. Flynn, J.M., Neher, S.B., Kim, Y.-I., Sauer, R.T. \& Baker, T.A. Mol. Cell 11, 671-683 (2003).

16. Neher, S.B., Flynn, J.M., Sauer, R.T. \& Baker, T.A Genes Dev. 17, 1084-1089 (2003)

17. Lee, C., Schwartz, M.P., Prakash, S., Iwakura, M. \& Matouschek, A. Mol. Cell 7, 627-637. (2001).

18. Kenniston, J.A., Baker, T.A., Fernandez, J.M. \& Sauer, R.T. Cell 114, 511-520 (2003).

19. Petroski, M.D. \& Deshaies, R.J. Mol. Cell 11, 1435-1444 (2003).

20. Janse, D.M., Crosas, B., Finley, D. \& Church, G.M. J. Biol. Chem. 279, 21415-21420 (2004).

21. Verma, R., McDonald, W.H., Yates, J.R. III \& Deshaies, R.J. Mol. Cell 8, 439-448 (2001).
How do cells know where they are and then use that information to differentiate into the appropriate cell type? The answer to the first part of the question depends on the establishment of morphogen gradients. Morphogens are extracellular molecules advance online publication 8 August 2004 (doi:10.1038/ nature02835)) now show that a cell's ability to interpret the concentration of at least one morphogen, Hedgehog $(\mathrm{Hh})$, depends not only on the number of active receptors but on the ratio of active to inactive receptors.

In flies, the Hh morphogen and its transmembrane receptor Patched (Ptc) are unusual in that the unbound receptor is the active form (panel a) and keeps the pathway 'off' by inhibiting another transmembrane protein, Smoothened (Smo). When $\mathrm{Hh}$ binds to Ptc the receptor is inactivated and the pathway is turned 'on' (panel b).

There are two models for how cells might perceive the amount of Hh. In the depletion model, only the number of inactive (bound) Ptc molecules would be important in determining the cell's response to signal. Thus, as the amount of $\mathrm{Hh}$ increases, the concentration of active Ptc would decrease and the Smo activity would increase. In the titration model, liganded Ptc would affect or titrate the inhibitory activity of unliganded Ptc so that the cell's perception of $\mathrm{Hh}$ concentration would depend on the ratio of bound (inactive) to unbound (active) Ptc. To distinguish between these two models, Casali and Struhl tested different levels of constitutively active Ptc

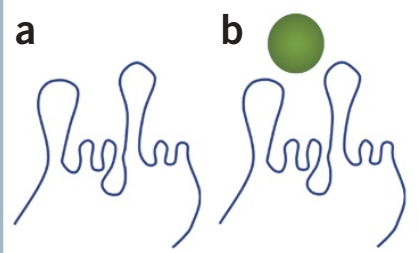

Ptc $\quad \mathrm{Hh}+\mathrm{Ptc}$

inactive
C

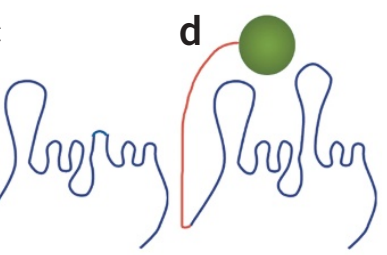

$\mathrm{Ptc}^{\Delta l o o p 2}$

constitutively active
Hh-Ptc

constitutively inactive (Ptc ${ }^{\Delta l o o p 2}$ ), a form of Ptc that cannot bind Hh but can still inhibit Smo (panel c). They asked whether the minimum amount of Ptc ${ }^{\Delta l o o p 2}$ needed to turn off the pathway depends on the presence of liganded Ptc (Hh-Ptc) (panel d). In the depletion model, the minimum level should be unaffected by liganded Ptc while in the titration model the presence of liganded Ptc should affect the amount of Ptc ${ }^{\Delta l o o p 2}$

required to keep the pathway off. Their experiments support the titration model and further show that relatively small few-fold differences in the ratio of unliganded to liganded Ptc may be enough to influence the full range of cell fates in response to the Hh gradient.

Of course how the ratio of liganded to unliganded Ptc affects Smo activity is still far from clear. Unliganded Ptc might function catalytically to inhibit Smo and the presence of liganded Ptc would titrate the catalytic activity of unliganded Ptc. Alternatively, the two forms could act stoichiometrically and compete for binding to Smo with opposite effects on Smo's activity. Finally, Ptc might act as a trimer, as proposed for the structurally related AcrB transporter. In this scenario, binding of any one monomer would block the ability of the multimer to function. Regardless, we now know that both forms of Ptc are relevant to how cells interpret the levels of $\mathrm{Hh}$.

Boyana Konforti 